\title{
A vivência da corporeidade por pessoas com deficiência visual por meio da Biodanza
}

\author{
Bodily experience through Biodanza in people with visual impairment \\ La vivencia de corporeidad en personas con deficiencia visual a través de la Biodanza
}

\author{
Helena Cristina Medeiros Vieira Schmidek'; Werner Robert Schmidek"'; Luiz Jorge Pedrão ${ }^{\prime \prime \prime}$
}

\begin{abstract}
RESUMO
Objetivo: refletir sobre a vivência da corporeidade por pessoas portadoras de deficiência visual. Conteúdo: são poucas as oportunidades oferecidas às pessoas portadoras de deficiência visual de experimentar o seu corpo em movimento, experienciar sua corporeidade, num mundo onde a conexão com o corpo está cada vez mais se distanciando no dia-a-dia. O método utilizado é trazido, principalmente, por Rolando Toro Araneda, no tocante à importância de ambientes pedagógicos, como a Biodanza, para que a vivência da corporeidade seja resgatada. Conclusão: este processo reflexivo permitiu considerar, que a prática da Biodanza pelas pessoas em questão, contribui no resgate da sua corporeidade, por possibilitar a ampliação de seus repertórios motores através da dança e de um reaprendizado emocional através da vivência. Oferece contribuição à enfermagem, uma vez que amplia o leque de possibilidades para a expansão do olhar empático do enfermeiro para essas questões, em sua prática profissional.
\end{abstract}

Descritores: Corporeidade, pessoas com deficiência visual; terapias complementares; Biodanza.

\begin{abstract}
Objective: to reflect on body experience in people with sight loss. Content: people with visual impairment are offered few opportunities to experience their body in motion and to experience their corporality, in a world where connection with the body is increasingly distant in daily life. The method used was drawn mainly from Rolando Toro Araneda, as regards the importance of teaching environments, such as Biodanza, for the experience of corporality to be restored. Conclusion: this reflective process made it possible to assert that, for the people in question, the practice of Biodanza contributed to restoring their corporality by enabling their motor repertoires to be expanded through dance and an emotional relearning through lived experience. It offers a contribution to nursing, since it broadens the range of possibilities for expanding nurses' empathetic regard to these issues as they practice their profession.

Descriptors: Corporality, visually impaired persons; complementary therapies; Biodanza.

\section{RESUMEN}

Objetivo: reflexionar sobre la vivencia de corporeidad en personas portadoras de deficiencia visual. Contenido: son pocas las oportunidades ofrecidas a las personas portadoras de deficiencia visual de tener la experiencia de su cuerpo en movimiento, de su corporeidad, en un mundo donde la conexión con el cuerpo está alejándose cada vez más en el cotidiano. El método usado lo aporta, principalmente, Rolando Toro Araneda, en lo que se refiere a la importancia de ambientes pedagógicos, como la Biodanza, para rescatar la vivencia de corporeidad. Conclusión: este proceso reflexivo permitió considerar que la práctica de Biodanza por las personas en cuestión, contribuye para el rescate de la corporeidad por posibilitar la ampliación de sus repertorios motores a través de la danza y de un reaprendizaje emocional a través de la vivencia. Contribuye también a la enfermería, ya que amplía el abanico de posibilidades para la expansión de la mirada empática del enfermero a esas cuestiones, en su práctica profesional.
\end{abstract}

Descriptores: Corporeidad, personas con daño visual; terapias complementarias; Biodanza.

\section{INTRODUÇÃO}

Do ponto de vista do cotidiano, supervalorizamos nossa visão, pelo fato de, culturalmente, ser essa dentre todas as outras possibilidades sensoriais, a mais requisitada na aquisição de conhecimento - um modelo visuocêntrico de construção de conhecimento ${ }^{1}$. Estima-se ser a visão responsável por $80 \%$ do nosso conhecimento ${ }^{2}$, um mundo organizado por pessoas que enxergam, dando à visão um papel essencial no desenvolvimento humano ${ }^{3}$. Dessa forma, é natural que o atendimento no serviço de saúde alicerce a relação interpessoal preferencialmente a partir desse canal de comunicação, que limita o acesso e a incorporação de informações significativas pela pessoa cega ${ }^{4}$, em detrimento a maneira de falar, tato, audição, olfato outros elementos comunicantes no atendimento na perspectiva da necessidade da pessoa com deficiência visual ${ }^{5}$.

'Zootecnista. Facilitadora de Biodanza. Doutoranda do Programa de Pós-Graduação em Enfermagem Psiquiátrica da Escola de Enfermagem de Ribeirão Preto/USP. São Paulo, Brasil. E-mail: hcmvieira@hotmail.com

"Médico. Professor Associado aposentado da Faculdade de Medicina de Ribeirão Preto/USP. São Paulo, Brasil. E-mail: werner.r.s@hotmail.com

'"'Enfermeiro. Professor Doutor do Departamento de Enfermagem Psiquiátrica e Ciências Humanas da Escola de Enfermagem de Ribeirão Preto/USP. São Paulo, Brasil. E-mail:

lujope@eerp.usp.br 
Deficientes visuais são aqueles que possuem limitação total ou parcial da visão, ou seja, sua construção de mundo externo ou interno não tem como matriz existencial os estímulos visuais. A deficiência visual pode ser total (cegueira) ou parcial (baixa visão); além disso, pode ser: congênita ou adquirida ${ }^{4}$. 0 primeiro tipo se refere às pessoas que já nascem sem o recurso da visão; elas não possuem imagens pré-formadas, inclusive a imagem corporal de si mesmo, o segundo tipo refere-se às pessoas que perderam a visão em algum momento da vida por causas diversas; possuem imagens mentais anteriores à deficiência ${ }^{6}$.

Num mundo centrado nos padrões adotados por e para videntes ${ }^{7}$ a identidade existencial dos deficientes visuais alicerça-se mais na sua não visão, do que, na potencialidade das suas outras capacidades de comunicação consigo e com o mundo.

Uma reflexão sobre a deficiência visual é relativa à teoria da substituição, segundo a qual a falta de um órgão seria compensada pelo melhor funcionamento de outros. Teoria equivocada que pressupõe a capacidade de adaptação do deficiente visual de forma simplista, ou seja, que a compensação da falta de visão pelos outros sentidos se daria de forma simples e automática e natural - o que é consequência de uma concepção biologizante e restritiva do ser humano ${ }^{3}$ e não como um resultado da aprendizagem ${ }^{8}$.

Para o deficiente visual, a matriz construtiva de mundo que não passa pela via do ver, possui nas outras formas de vivenciar o corpo, a base para a relação consigo mesmo, com o outro e com o mundo. Um corpo que não deveria ser reduzido principalmente ao tato, mas sim, includente de outras possibilidades, que, até para nós videntes, são difíceis de descrever, devido a nossa própria experiência bastante vinculada ao conhecer o mundo a partir do ver.

O presente estudo constitui uma reflexão fundamentada em base teórica desenvolvida por Rolando Toro Araneda, que, por meio da Biodanza, propõe um processo de aprendizagem pedagógica e desenvolvimento pessoal, realizado em grupo, num ambiente cooperativo, em que os indivíduos vivenciem sua expressão no aqui e no agora, por meio do movimento corporal, de maneira integrada, ou seja, que sua expressão seja uma resultante congruente do seu pensar e do seu sentir?

Etimologicamente, Biodanza significa 'dança da vida', a união do prefixo grego 'bio' (vida) com 'dança'. Um sistema vivencial definido como um sistema de integração humana, de renovação orgânica, de reeducação afetiva e de reaprendizagem das funções originais da vida, que consiste em induzir vivências integradoras por meio da música, do canto, do movimento e de situações de encontro em grupo ${ }^{9}$.

A pouca habilidade para perceber e traduzir a comunicação não verbal no atendimento ${ }^{4,10}$ faz com que o cego enfrente barreiras de comunicação com os profissionais de saúde, dentre eles os enfermeiros, que desconhecem técnicas de comunicação adaptadas às necessidades desta população, comprometendo a eficácia assistencial ${ }^{11,12}$.

Não é objetivo dessa reflexão instrumentalizar os profissionais de saúde sobre como melhorar essa comunicação interpessoal, embora seja um elemento importante na consulta da enfermagem, e sim refletir na perspectiva do grupo social estudado, a importância da vivência da corporeidade no processo de desenvolvimento pessoal em pessoas portadoras de deficiência visual, num momento cultural em que a correria do dia a dia, nos distancia, videntes e não videntes da experiência do corpo.

\section{CONTEÚDO}

Olhamos e nomeamos, olhamos e definimos, olhamos e identificamos. Intensificamos e naturalmente aprimoramos o nosso olhar para fora, para o externo. A partir de um olhar que inicialmente vê a superfície do que se vê, a aparência, podemos ampliar e aprofundar nosso olhar de maneira crítica, que possui, na sua essência, uma avaliação racional e analítica do que se vê, provinda de raízes fortes e estruturadas de nosso modo cultural cartesiano de decodificação e construção de mundo.

Recebemos pouco incentivo cotidiano para o desenvolvimento de um olhar observador contemplativo, suavizado de julgamentos ao que se olha; e menos incentivo temos em desenvolver um olhar sensível, emocionado, afetivo, menos visível aos nossos olhos e mais visível ao nosso olhar sentido. Ousa-se pouco aventurarmo-nos na subjetividade da própria visão que a cegueira nos permite enxergar, ou seja, ver não só com o aparelho biológico e específico, os olhos, que com indiscutível eficiência nos proporciona materializar em forma, nome e sentido o mundo.

Ao estudar o universo da deficiência visual, nota-se dois polos opostos quando se fala em cegueira: o cego pode ser visto como indefeso, como um coitado; ou como detentor de um saber sobrenatural, mais capacitado para desvendar mistérios do que os videntes ${ }^{13}$. Ambos os rótulos, respectivamente, coitadinho ou herói, embora antagônicos, são dois lados da mesma moeda. Sendo o fio que os une e os separa, a idealização. Ambos os rótulos trazem sérios prejuízos a esse grupo da população, seja pela subvalorização dos sentidos (insensivelmente desconsideradas) ou supervalorização dos sentidos (excessivamente destacadas). 
Ao debruçar-se sobre questionamentos de saúde e adoecimento mental na população cega, fatores biológicos desempenham um papel importante, mas não determinante (predispõem, mas não determinam); fatores sociais também ocupam um lugar de destaque, e, embora o fator biológico não seja determinante os deficientes visuais - e especificamente os portadores de cegueira - constituem um grupo de risco em termos de saúde mental ${ }^{14,15}$, não só associada ao menor bem-estar e maior sofrimento psicológico, mas também à menor qualidade de vida, menor capacidade de desenvolvimento pessoal e maior dificuldade na conquista de uma plena integração social ${ }^{14}$.

A vivência do mundo inicia-se pelo corpo, pelo sensorial, sendo, portanto, um processo natural, onde constantemente reconstruímos nossa definição, externa e interna, e interagimos com o mundo através de uma corporeidade desenvolvida a partir da percepção sensorial-emocionada dos nossos sentidos.

Nessa perspectiva, a construção da identidade do deficiente visual sofre um duplo impacto limitante no desenvolvimento da sua expressão existencial: primeiro pela natural limitação visual orgânica, mas também, por uma limitação cultural dadas as poucas oportunidades que possuem de experienciar-se através da sua corporeidade ampliada $^{16}$. A compreensão do corpo somente é possível a partir das experiências vivenciadas nas relações, estabelecidas consigo, com os outros, com o mundo e com as coisas. A complexidade do existir humano se plenifica na sua forma simbólica de ser significado e significante e, ao mesmo tempo, de dar significação para as coisas do mundo, a partir da sua capacidade de percebê-lo, antes mesmo de qualquer pensamento determinante ${ }^{17}$.

A corporeidade não pode ser vista apenas como apêndice ou complemento educacional, é preciso que ela seja seu ponto de partida e não de chegada ${ }^{18}$ já que se apresenta como a forma mais autêntica do humano ser representado no mundo vivido ${ }^{19}$.

Estar apropriado corporalmente de si, inclui estar receptivo, saber reconhecer, e ter prontidão ativa a responder afastando-se de estímulos externos que não estejam em ressonância com uma vida de saúde. É reconhecer que somos seres integrais e que todas as nossas dimensões (cognitiva, física, social, emocional e espiritual) são interconectadas e interdependentes umas com as outras ${ }^{18,20,21}$

O modo cartesiano de visão de mundo direciona o nosso olhar no mundo para o que é objetivo e racional, diminui a oportunidade de integrarmos na vida cotidiana com elementos essenciais vinculantes consigo e com o mundo, tais como: emoção, sentimento, intuição e sensibilidade. O cotidiano para o deficiente visual, segue o mesmo fluxo, já que toda a metodologia desenvolvida para auxiliá-lo a inserir-se no cotidiano das atividades diárias, obedece ao mesmo padrão, que é pautado na memorização e retenção de conhecimento predominantemente racional de suas habilidades sensoriais.

Com o desenvolvimento e a influência do modelo cultural, estamos aos poucos nos desconectando de nós mesmos, a corporeidade, ou seja, a maneira pela qual o indivíduo sente e utiliza o corpo como ferramenta de manifestação e interação com o mundo vai aos poucos perdendo seu status de importância e já não é tão relevante como fonte de informação de nós no mundo ${ }^{18}$.

Baseado na compreensão holística e integral do conceito atual do Ser é necessário criar espaços pedagógicos ao deficiente visual em que possam ser proporcionadas oportunidades onde a conexão com a realidade passe pela expressão corporal emocionada do sujeito, o qual, habitando naturalmente do seu corpo, reconhece-o e o utiliza na máxima integralidade possível como instrumento relacional com o mundo ${ }^{9,18}$.

A fenomenologia da corporeidade não é descrever um corpo, mas sim a qualidade e os significados de uma experiência, que esteja intimamente relacionada com esse corpo, um corpo que se expressa subjetivamente ${ }^{18}$. Observações das representações de pessoas portadoras de deficiência visual sobre a organização espaço-temporal tomando como referência seu próprio corpo, permitiu a interpretação de que, se bem elaborada as sensações e emoções corporais, não é preciso só dos olhos, mas do corpo inteiro, para olhar, ver e enxergar ${ }^{22}$.

Destaca-se que na Biodanza consideramos a função do contato terapêutica, pois ela pode dissolver as tensões musculares crônicas, mas, é importante compreender que o contato em si mesmo, mecânico não é terapêutico. Sendo assim, possibilitar um processo de transição progressivo do contato mecânico, a expressão do corpo sensibilizado sensorialmente, ao corpo emocionado afetivamente e de maneira empática é possibilitar a ele próprio descobrir-se, assim como resgatar e cultivar expressões existenciais de saúde ${ }^{9}$.

Deslocar o nosso olhar da falta, para expandir sim, nossa dimensão existencial sã, já existente, é fundamental na restauração da saúde mental $\left.\right|^{9,23,24}$. O cotidiano reforça a doença, a falta, a carência; nesse caso especificamente, a visão. Deixando de lado a valorização, incentivo, construção e reconstrução de um mundo interno e externo o qual já se expressa a partir de uma corporeidade que inclui o não enxergar, porém não se limita a ele.

Assim, precisamos educar o indivíduo com necessidades educacionais especiais enquanto um todo, ou seja, nas suas diferentes dimensões (cognitiva, física, emocional, social e espiritual) e nas suas relações com o mundo à sua volta. 
Dessa forma, o pleno aproveitamento do nosso aparato sensorial não depende da quantidade de órgãos dos sentidos que possuímos, mas sim, das oportunidades qualitativas que recebemos para desenvolvê-los. É preciso que se dê espaço para que surja o indivíduo que, apesar do que faz ou do que deixa de fazer e, do porque faz ou deixa de fazer, é indivíduo, nem sempre normal, nem sempre doente; nem sempre com limitações, mas também com limitações. É indivíduo e não doença. É indivíduo e não 'normalidade'. É indivíduo e não 'patologia'25.

Biodanza, é uma atividade que, necessariamente, se realiza em grupo. A cada aula se propõem exercícios que facilitem o próprio indivíduo a encontrar em si a sua expressão integrada (pensamento-sentimento; mente-corpo), potencialidades positivas de ajustamento individual e social pela expressão de movimento (dança). Um processo de desenvolvimento pessoal, um método vivencial, que possibilita organicamente um redescobrir-se na relação consigo e com os outros através de exercícios estruturados numa sequência determinada, estimulado por músicas específicas.

Movimentos naturais (caminhar, saltar, espreguiçar-se, ...), gestos ligados aos "costumes sociais" (dar a mão, abraçar, embalar, ...) e os gestos arquetípicos (cuidar, dar, receber, ...) são os modelos naturais humanos em que se baseiam os exercícios de Biodanza.

A dança contida no método da Biodanza tem sua definição baseada na antropologia e não tem relação com o alcance de uma determinada performance física e tampouco envolve competição, comparação ou espetáculo na Biodanza. Origina-se de um impulso deflagrado pela música que associado a uma emoção interna, comove e move, transformando exercícios específicos em vivências estruturados a partir de gestos naturais do ser humano destinados a ativar a potencialidade afetiva que nos conecta a nós mesmos, ao semelhante e ao universo ${ }^{9}$. Um momento íntimo de autenticidade expressiva, que vai se construindo aos poucos à medida que a confiança em si e no grupo se estabelecem: a vivência.

A vivência é à base da Biodanza, sendo definida, então, como a experiência vivida com grande intensidade por um indivíduo no momento presente, atentos às sensações cenestésicas, vínculos de afeto consigo, autoregulação entre suas possibilidades e limites, através do constante convite a uma conexão com a sua corporeidade e a expressão do que sente. Uma experiência de profunda conexão íntima do indivíduo consigo mesmo (ligada ao ser a e à percepção de estar vivo), original (anterior a qualquer elaboração simbólica ou racional de nós mesmos), espontânea, subjetiva, integradora (sentir e pensar) vivida no momento presente do aqui e do agora. Uma música, que ligada aos gestos e aos movimentos corporais coerentes com ela, produzirá, em cada um, vivências semelhantes, ainda que de intensidades e matizes diferentes, de acordo com o nível de repressão e sensibilidade pessoal ${ }^{9}$.

Destacamos que dançar para a pessoa portadora de deficiência visual é “'ver' com o corpo o que os olhos não podem enxergar; é ultrapassar os limites impostos pela deficiência visual"13. Possibilitar a expressão motora, movimentar-se sem o auxílio de outras pessoas, promover experiências de interação social, para o deficiente visual, passa a ser uma possibilidade de autonomia adquirida passo-a-passo em um processo contínuo.

A partir dos exames dos sentidos vivenciados pelos sujeitos no contexto da Biodanza, chegou-se à compreensão de que nela a dança se configura nas metamorfoses do corpo, como expressão da identidade e como experiência da identidade e da alteridade. Quando nos relacionamos em grupo é preciso conhecer a diferença, compreender a diferença e aprender com a diferença, respeitando o indivíduo como ser humano. Nesse aspecto, a Biodanza também contribui na construção do indivíduo psicossocial saudável. Contribui também socialmente para uma organização coletiva includente da diversidade ${ }^{26}$.

\section{CONCLUSÃO}

Há carência de estudos que busquem aprofundar a compreensão do aprendizado pelo corpo e consequente expressão no mundo para pessoas portadoras de deficiência visual.

Consideramos, a partir da reflexão apresentada, que a prática da Biodanza por pessoas portadoras de deficiência visual, congênita ou não, tem potencial para contribuir no resgate da sua corporeidade, por possibilitar ampliação de seus repertórios motores (através da dança) e de um reaprendizado emocional (através da vivência), onde novos vínculos afetivos positivos consigo, com a vida e com o grupo social no qual estão inseridos podem ser reestabelecidos.

Reflexões como esta apresentada oferece importante contribuição à enfermagem, uma vez que amplia o leque de possibilidades para a expansão do olhar empático do enfermeiro no sentido de compreensão da importância da corporeidade para esse grupo social e assegurando que a assistência ocorra de forma eficiente, contemplando as necessidades de ambas as partes no processo interpessoal.

\section{REFERÊNCIAS}

1. Moraes M. Cegueira e Cognição: sobre o corpo e suas redes. Ver. de Antropología Iberoamericana. Madrid. [Internet]. 2005 [cited 2019 May 29]. Available from: http://www.aibr.org/antropologia/44nov/articulos/nov0514b.pdf 
2. Oliveira JVG. Do essencial invisível: arte e beleza entre os cegos. Rio de Janeiro: Revan/FAPERJ; 2002.

3. Nunes SS, Lomônaco JFB. The blind student: prejudices and potentialities. Psicol. Esc. Educ. [Internet]. 2010 [cited 2019 May 28]; 14(1), 55-64. Available from: http://www.scielo.br/pdf/pee/v14n1/v14n1a06.pdf/Similarpages

4. Soares JR, Pagliuca LMF, Barbosa EMG, Maia ER. Knowledge acquisition on communication with blind patients in nursing consultatio. Rev Rene. [Internet]. 2018 [cited 2019 May 29]; 19:e3490. DOI: http://dx.doi.org/10.15253/2175-6783.2018193490

5. Barbosa GO, Wanderley LD, Rebouças CB, Oliveira PM, Pagliuca LMF. Development of assistive technology for the visually impaired: use of the male condom. Rev. Esc. Enferm. USP. [Internet] 2013 [cited 2019 May 29]; 47(5):1158-64. DOI: http://dx.doi.org/10.1590/S0080-623420130000500021.

6. Cazé CMJO, Oliveira AS. Dança além da visão: possibilidades do corpo cego. Pensar a Prática. [Internet] 2008 [cited 2019 May 27]; 11(3), 293. Available from: https://www.revistas.ufg.br/fef/article/view/3592/4263

7. Masini E. O perceber e o relacionar-se do deficiente visual. Coordenadoria Nacional para a integração da pessoa portadora de deficiência. Brasília (DF). [Internet] 1994 [cited 2019 May 28]. Available from: http://www.deficienciavisual.pt/txt-perceberrelacionarDV.htm\#II-A.

8. Lomônaco JFB, Nunes SS, Sano WT. Concepções de cegueira de estudantes de um curso de psicologia. Boletim de Psicologia. 2004 [cited 2019 May 28]; 54(120): 23-46. Available from: https://bdpi.usp.br/item/001483341.

9. Toro, R. Biodanza. Tradução de Marcelo Tápia. São Paulo: Edições 2/Editora Olavobrás/EPB; 2005.

10. Bax AM, Araujo ST. No verbal expression from the patient in care: perception of the nurse in cardio intensive care unit. Esc. Anna Nery [Internet]. 2012 [cited 2019 May 29]; 16(4): 728-733. DOI: http://dx.doi.org/10.1590/S1414-81452012000400012.

11. Martins KP, Costa KNFM, Rezende LCM, Gomes TM, Dantas TRA, Santos SR. Perception of nursing staff about physical accessibility and communication of people with visual impairment. Ciênc. Cuid. Saúde. [internet] 2015 [cited 2019 May 28]; 14(2):1019-26. DOI: http://dx.doi.org/10.4025/cienccuidsaude.v14i2.22045

12. Shamshiri M, Mohammadi N, Cheraghi, MA, Vehviläinen-Julkunen K, Sadeghi T. Disciplined care for disciplined patients: experience of hospitalized blind patients. Holist Nurs Pract. [internet] 2013 [cited 2019 May 29]; 27(6):344-8. Available from: https://insights.ovid.com/pubmed?pmid=24121699

13. Amiralian MLTM. Compreendendo o cego: uma visão psicanalítica da cegueira por meio de desenhos-estórias. São Paulo: Edição/Editora Casa do Psicólogo. [Internet] 1997 [cited 2019 May 28]. Available from: http://www.deficienciavisual.pt/txtcompreendendo-cego.htm\#C2

14. Garcia MRS. Cegueira Congénita e Adquirida: Implicações na Saúde Mental e Resiliência [master thesis]. Lisboa: Universidade Lusófona de Humanidades e Tecnologias. [Internet] 2014 [cited 2019 May 27]. Available from: http://recil.grupolusofona.pt/handle/10437/6424

15. Wylie L, McAllister BD, Marshall J. Changing practice: Implications of the world report on disability for responding to communication disability in under-served populations. Int J Speech Lang Pathol. [Internet] 2013 [cited 2018 May 29]; 20(1):1-13 DOI: https://doi.org/10.3109/17549507.2012.745164

16. Porto E. A corporeidade do cego. Novos olhares. Piracicaba: Editora: Memnom. 2005.

17. Guedes CM. Corpo: tradição, valores, possibilidades do desvelar [master thesis]. Campinas: Faculdade de Educação Física, Unicamp; 1995. http://repositorio.unicamp.br/handle/REPOSIP/275269

18. Leite PFMC, Alexandrino DFL, Lima CL. CORPO, Corporeidade e deficiência: buscando relações, tecendo alternativas. In: Anais do Congresso de Pesquisa e Extensão da UEMG/Barbacena. [Inernet] 2015 [cited 2018 Dec 17]. Available from: http://revista.uemg.br/index.php/anaisbarbacena/article/view/823/530.

19. Assmann H. Paradigmas educacionais e corporeidade. Piracicaba: Editora Unimep; 1995.

20. Souza DL. Holistic education: learning from the experiences of three holistic teachers [doctoral dissertation]. Cambridge: Harvard Graduate School of Education; 2000.

21. Rocha DLS. Educação Holística: Características e Reflexões. Edição: Eyng, AN; Ens RT, Junqueira SRA. O tempo e o espaço na escola: o cotidiano escolar. Curitiba: Champagnat; 2003.

22. Santos A. Representações de pessoas cegas sobre a organização espaço-temporal tomando como referência seu próprio corpo [master thesis]. Rio de janeiro: Faculdade de Educação Física, Universidade Gama Filho; 1996.

23. Santin S, Simmons JN. Problemas das crianças portadoras de deficiência visual congênita na construção da realidade. Revista Benjamin Constant [Internet] 2000. [cited 2018 Nov 18]. Available from: http://www.ibc.gov.br/images/conteudo/revistas/benjamin_constant/2000/edicao-16agosto/Nossos_Meios_RBC_RevAgo2000_ARTIGO1.pdf.

24. Batista CG. Formação de conceitos em crianças cegas: questões teóricas e implicações educacionais. Psicol. teor. pesqui. [Internet] 2005 [cited 2019 May 27]; 21(1): 7-15. Available from: http://www.scielo.br/pdf/ptp/v21n1/a03v21n1

25. Fiorentin S, Lustosa NP, Rocha DLS. (2004). Resgatando o papel do corpo e da corporeidade nos processos de ensino e aprendizagem na educação especial. In: Congresso Internacional de Educação; 2004. São Luiz do Maranhão, 2004.

26. Reis AC. Dance of Life: Aesthetics Experience of Biodanza [doctoral dissertation]. São Paulo: Instituto de Psicologia, Universidade de São Paulo. [Internet] 2012 [cited 2019 May 27]. DOI: http://dx.doi.org/10.11606/T.47.2012.tde-15062012111437. 